\section{Commentary: (Preoperative) size matters: Pulmonary artery reinterventions after arterial switch operation}

\author{
Stephen Clark, MD, ${ }^{\mathrm{a}}$ and Robert D. B. Jaquiss, MD ${ }^{\mathrm{b}}$
}

The arterial switch operation (ASO) remains the gold standard therapy for patients with dextro-transposition of the great arteries (d-TGA), with low early mortality rates of $1 \%$ to $3 \%$ and long-term survival rates $>90 \%$ at 15 , 20 , and 25 years. ${ }^{1-4}$ Now that ASO patients are expected to survive the operation, attention has been shifted to short- and long-term morbidity. ${ }^{2-5}$ Branch pulmonary artery stenosis (BPAS) has been identified as the most common indication for reintervention in d-TGA patients following ASO., ${ }^{2,5}$ Luo and colleagues ${ }^{6}$ analyzed the relationship of preoperative features to postoperative reintervention for BPAS. In their large, single-center cohort of 262 patients, the authors report early PA reintervention rate of $10.7 \%$, an unusually high number attributed to early detection of BPAS by utilizing intraoperative epicardial echocardiography. Patients undergoing early PA intervention also had a late reintervention rate of $24 \%$, whereas only $9.4 \%$ of those without early reintervention required late reintervention, at a median follow-up of 20.8 months. Although no predictive factors were identified for early branch PA reintervention, smaller preoperative left PA (LPA) and right PA (RPA) dimensions were independently associated with late branch PA reintervention on multivariable analysis. Additionally, the authors found that LPA and RPA dimensions were significantly

From the ${ }^{\mathrm{a}}$ Division of Pediatric Cardiology, Department of Pediatrics and ${ }^{\mathrm{b}}$ Division of Pediatric Cardiothoracic Surgery, Department of Thoracic and Cardiovascular Surgery, University of Texas Southwestern Medical Center \& Children's Health System of Texas, Dallas, Tex.

Disclosures: The authors reported no conflicts of interest.

The Journal policy requires editors and reviewers to disclose conflicts of interest and to decline handling or reviewing manuscripts for which they may have a conflict of interest. The editors and reviewers of this article have no conflicts of interest.

Received for publication Nov 6, 2021; revisions received Nov 6, 2021; accepted for publication Nov 8, 2021; available ahead of print Nov 12, 2021.

Address for reprints: Robert D. B. Jaquiss, MD, Division of Pediatric Cardiothoracic Surgery, Department of Thoracic and Cardiovascular Surgery, University of Texas Southwestern Medical Center \& Children's Health System of Texas, 1935 Medical District Dr, Dallas, TX 75235 (E-mail: Robert.jaquiss@utsouthwestern.edu).

J Thorac Cardiovasc Surg 2022;164:328-9

$0022-5223 / \$ 36.00$

Copyright (c) 2021 by The American Association for Thoracic Surgery

https://doi.org/10.1016/j.jtcvs.2021.11.012

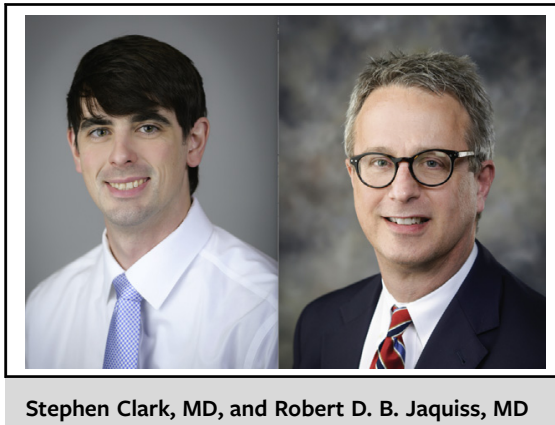

CENTRAL MESSAGE

Branch pulmonary artery stenosis is not uncommon after the arterial switch operation, and its late occurrence is associated with smaller preoperative branch pulmonary artery size.

smaller on postoperative discharge echocardiograph compared with preoperative baseline. A notable finding was the relative futility of catheter-based intervention for early BPAS.

Multiple mechanisms for BPAS following ASO have been proposed, ${ }^{7}$ and multiple surgical techniques have been employed with hopes of improving outcomes. ${ }^{8,9}$ Although this study does not address technical considerations of the ASO, it does point out a need for possible modification to standard ASO in those patients with smaller branch PAs on preoperative assessment. Furthermore, this study is the first to show smaller preoperative LPA and RPA size to be predictive of late PA reintervention. Given this study's single-institution design with consistent surgical technique, it is unclear whether or not these findings would hold true for ASO performed in other centers.

With improved survival in patients following neonatal ASO for d-TGA, focus has turned to reducing long-term morbidity in this population, including BPAS, its most common complication. The authors should be congratulated for identifying preoperative risk factors that may alert surgeons and cardiologist to those at particular risk for this condition. Although the present study is another step toward understanding postoperative BPAS, additional research is needed to determine whether or not modified surgical techniques may reduce the need for postoperative PA reintervention. In the meantime, it would be understandable 
if surgeons planning an ASO were to give serious consideration to preemptive augmentation of smallerthan-usual branch pulmonary arteries. Given the high rates of multiple PA reinterventions in this study, it is also clear that there continues to be room for improvement in managing these complications by both surgical and transcatheter approaches.

\section{References}

1. Fraser CD, Chacon-Portillo MA, Well A, Zea-Vera R, Binsalamah Z, Adachi I, et al. Twenty-three year experience with the arterial switch operation. Expectations and long-term outcomes. Semin Thorac Cardiovasc Surg. 2020;32:292-9.

2. Khairy P, Clair M, Fernandes SM, Blume ED, Powell AJ, Newburger JW, et al. Cardiovascular outcomes after the arterial switch operation for d-transposition of the great arteries. Circulation. 2013;127:331-9.

3. Fricke TA, Buratto E, Weintraub RG, Bullock A, Wheaton G, Grigg L, et al. Long-term outcomes of the arterial switch operation. J Thorac Cardiovasc Surg. 2022;163:212-9.
4. Santens B, Van De Bruaene A, De Meester P, Gewillig M, Troost E, Claus P, et al Outcomes of arterial switch operation for transposition of the great artery. A 35-year follow-up study. Int J Cardiol. 2020;316:94-100.

5. Michalak KW, Moll JA, Sobczak-Budlewska K, Moll M, Dryzek P, Moszura T, et al. Reoperations and catheter interventions in patients with transposition of the great arteries after the arterial switch operation. Eur J Cardiothorac Surg. 2017;51:34-42.

6. Luo S, Haranal M, Deng XM, Varenbut J, Runeckles K, Fan SC, et al. Branch pulmonary artery stenosis after arterial switch operation: the impact of preoperative anatomic factors on reintervention. I Thorac Cardiovasc Surg. 2022;164:317-27.e8.

7. Morgan CT, Mertens L, Grotenhuis H, Yoo SJ, Seed M, Grosse-Wortmann L. Understanding the mechanism for branch pulmonary artery stenosis after the arterial switch operation for transposition of the great arteries. Eur Heart $J$ Cardiovasc Imag. 2017;18:180-5.

8. Rudra HS, Mavroudis C, Backer CL, Kaushal S, Russell H, Stewart RD, et al. The arterial switch operation: 25-year experience with 258 patients. Ann Thorac Surg. 2011;92:1742-6.

9. Swartz MF, Sena A, Atallah-Yunes N, Meagher C, Cholette JM, Gensini F, et al Decreased incidence of supravalvar pulmonary stenosis after arterial switch operation. Circulation. 2012;126(suppl 1):S118-22.
See Article page 317

\section{Commentary: Branch pulmonary artery stenosis after the arterial switch operation: Is prevention better than cure?}

\author{
Minoo N. Kavarana, MD, FACS
}

The arterial switch operation (ASO) has revolutionized the surgical management of children with transposition of the great arteries with neonatal repairs being performed at many centers with good results. ${ }^{1}$ Despite distinct advantages over the earlier and almost obsolete atrial switch repair, ${ }^{2}$ postoperative branch pulmonary artery (PA) stenosis remains the Achille's heel of a successful ASO. ${ }^{3}$

\footnotetext{
From the Section of Pediatric Cardiothoracic Surgery, Medical University of South Carolina, Charleston, SC.

Disclosures: The author reported no conflicts of interest.

The Journal policy requires editors and reviewers to disclose conflicts of interest and to decline handling or reviewing manuscripts for which they may have a conflict of interest. The editors and reviewers of this article have no conflicts of interest.

Received for publication Nov 12, 2021; revisions received Nov 12, 2021; accepted for publication Nov 16, 2021; available ahead of print Nov 20, 2021.

Address for reprints: Minoo N. Kavarana, MD, FACS, Section of Pediatric Cardiothoracic Surgery, Department of Surgery, 10 McClennan Banks Dr, SJ 2190 N/MSC 918, Charleston, SC 29425 (E-mail: kavarana@musc.edu).

J Thorac Cardiovasc Surg 2022;164:329-30

$0022-5223 / \$ 36.00$

Copyright (c) 2021 by The American Association for Thoracic Surgery

https://doi.org/10.1016/j.jtcvs.2021.11.039
}

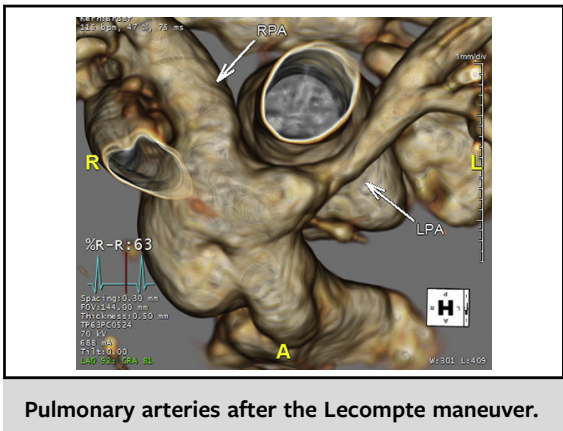

CENTRAL MESSAGE

The Lecompte maneuver has proved to be an essential part of the arterial switch operation. However, the stretch imparted might exacerbate the stenosis in small-branch pulmonary arteries.

The Toronto group analyzed 262 consecutive children with dextro-transposition of the great arteries who underwent the ASO to evaluate the effect of preoperative anatomic factors on postoperative branch PA stenosis. ${ }^{4}$ There were 28 early branch PA interventions (10.6\%) concomitant $(\mathrm{n}=20)$ or during the intensive care unit stay $(\mathrm{n}=10)$. Seven percent were secondary to complex coronary artery anatomy. Patients who had branch PA reintervention had more right ventricular (RV) dysfunction, 